\title{
Development and validation of the conservation of resources scale for COVID-19 in the Chinese adult general population
}

\author{
Yanqiu Yu ${ }^{1} \cdot$ Joseph T.F. Lau ${ }^{1} \cdot$ Mason M.C. Lau ${ }^{1}$ \\ Accepted: 27 May 2021 / Published online: 17 June 2021 \\ (C) The Author(s), under exclusive licence to Springer Science+Business Media, LLC, part of Springer Nature 2021
}

\begin{abstract}
Globally, the coronavirus disease 2019 (COVID-19) pandemic has caused severe and multi-dimensional resource losses among individuals. The Conservation of Resource (COR) theory postulates that resource loss generates related stress responses. It can suitably be applied to understand the pandemic's encompassing adverse consequences. Yet, no assessment tool exists. This study hence developed and validated the COR Scale for COVID-19 (CORS-COVID-19) to facilitate relevant research. The five hypothesized domains included losses in financial resource, family resource, future control, fun, and social resource. A population-based random telephone survey interviewed 300 Chinese adults in the general population in Hong Kong, China during April 3-10, 2020. The levels of different types of resource losses were high (especially for loss in fun). The 5-factor structure identified by factor analysis matches with the five hypothesized dimensions. Its psychometric properties are acceptable, including good internal consistency, content validity (the correlations between the items and their respective subscales were stronger than that between the items and the other four subscales), concurrent validity (significant correlations between the scale/ subscale scores and both emotional distress due to COVID-19 and satisfaction with living in Hong Kong), and convergent validity (significant correlations between specific subscales and corresponding external variables). Relatively high floor effects were detected in some subscales. The scale, which is the first of the types to assess resource losses during a pandemic, can provide theory-based understandings/assessment about the negative impacts of COVID-19. It also facilitates warranted comparisons across countries and time periods in future studies.
\end{abstract}

Keywords COVID-19 $\cdot$ Resource loss $\cdot$ Conservation of resource $\cdot$ Validation $\cdot$ China

\section{Introduction}

The Coronavirus Disease 2019 (COVID-19) pandemic has accumulated over 131 million confirmed cases and over 2.85 million deaths as of April 6, 2021 (World Health Organization, 2021). Globally, many governments have implemented unprecedentedly strict social distancing measures, which have caused serious and multi-dimensional damages to people's lives and mental health (Bouali et al., 2020; Ilesanmi \& Afolabi, 2020). For instance, prevalent mental distress (e.g., depression and acute stress disorder) has been resulted (Venkatesh \& Edirappuli, 2020). Actual and perceived

Joseph T.F. Lau

jlau@cuhk.edu.hk

1 Centre for Health Behaviours Research, Jockey Club School of Public Health and Primary Care, The Chinese University of Hong Kong, Sha Tin, N.T., Hong Kong, China resource losses, which are potential causes of mental distress, are almost inevitable and universal during the COVID-19 pandemic and afterward. Economically, recessions are emerging and unemployment rates are soaring in many countries (Bartik et al., 2020). Social interactions have been interrupted tremendously (Adalja et al., 2020). In many countries, there is emerging politicization of COVID-19 as well as controversies and protests concerning resource losses due to lockdowns and social distancing. Uncertainty prevails as there are multiple waves of resurges in the number of new cases in many countries. It is warranted to understand the types and extents of people's resource losses, presently and in the future 'new normal' world.

Mental distress during the COVID-19 pandemic is a serious concern. Depression and anxiety have widely been reported across populations and countries during the COVID-19 pandemic (Pappa et al., 2020; Qiu et al., 2020; Rahmatipour et al., 2020). Furthermore, mental distress due to COVID-19 may become a chronic condition (e.g., post-traumatic stress disorder) (Liang et al., 2020). Previous studies investigating 
factors of mental distress during COVID-19 mainly focused on related cognitions (Choi et al., 2020; Yu et al., 2021); a dearth of such studies was theory-based, nor considered the important perspective of resource losses. In literature, however, resource loss is the strongest predictor of the severity and duration of mental distress related to traumatic events (Blaze \& Shwalb, 2009; Freedy et al., 1994). The resource losses due to COVID-19 have reduced people's coping resources (Hobfoll, 1989), and may thus increase mental distress. This present study hence developed and validated a tool that can be used to assess various types of resource losses systematically.

This tool was based on the Conservation of Resource (COR) theory, which offers an important potential framework to analyze how various types of resource losses would affect behavioral and emotional responses related to the COVID-19 pandemic. The COR theory is built upon the claim that all people are concerned about and motivated to conserve their resources, as resources mean things they value (Hobfoll, 1988, 1989, 2004a, 2011). Stress arises as a response to the occasions/events of which resources have been or might be lost (Hobfoll, 1988, 1989, 2004a, 2011). It thus posits that the occurrence of stressful events would result in resource losses, which would cause negative personal, social, and material outcomes such as mental distress and undesirable behaviors (Holmgrenn et al., 2017). The theory thus emphasizes the objective nature of stress. Empirically, it has been widely used to explain emotional distress in the contexts of natural disasters (Benight et al., 1999; Freedy et al., 1994), diseases (Taylor et al., 2006), and violent political movements (Hall et al., 2015; Hou et al., 2015). The theory is certainly applicable to the context of COVID-19 for the following reasons. First, resource loss due to COVID-19 is almost universal. Second, such losses have impacted mental health substantially and may affect preventive behaviors. Third, the theory has been applied to look at traumatic stress which often evaporates resources. To many people, COVID-19 is traumatic as it suddenly changes lifestyles completely, presents a serious health threat, and causes unexpected financial losses (e.g., unemployment).

The COR theory involves some major principles and corollaries. First, resource loss is far more salient than resource gain, i.e., losing a resource would have greater psychological impacts than gaining the same resource, which has explained people's cognitive bias in preventing losses versus striving for gains and supported empirically (Holmgrenn et al., 2017). This is particularly relevant to COVID-19, which involves more losses than gains. Second, people have to invest resources in order to conserve or gain resources (e.g., investing in health to gain wealth). In the context of COVID-19, people need to invest resources in behaviors (e.g., social distancing and working from home) to conserve resources (e.g., health and financial resources). Third, the theory postulates the phenomenon of "loss spirals", meaning that those who have fewer resources are more likely to lose resources and also tend to lose more resources in the future. To prove the claim and to serve the disadvantaged groups, the new COR tool is well suited to study resource losses among the low-resourced group over time. Such studies were found in literature (Holmgrenn et al., 2017). As resources can be culturally shaped, the theory considers the cultural dimensions of the relationships between resources and stress. It reminds that a COR tool needs to assess resources contextually, and crosscultural validation is important. Furthermore, the theory has been applied to look at associations with mental distress, chronic illness management, health risk behaviors, and the healthcare system. The new tool may thus be used to investigate a wide range of emotional/behavioral responses to COVID-19. The COR theory thus offers an important perspective that resource losses due to the COVID-19 pandemic are essential in explaining mental distress during the pandemic.

According to the COR theory, losses may involve personal, social, and material resources (Hobfoll, 2004a; Hou et al., 2015). Personal resources refer to internal resources that can be either physical (e.g., health and mobility) (Ryan et al., 2008) or psychological (e.g., sense of control over one's life and optimism) (Diener et al., 2003). Material resources refer to personal possession in general (e.g., assets and properties); employment can be categorized as material resources (Ryan et al., 2008). Social resources refer to external resources that are rooted in interpersonal interactions (e.g., social relationship) (House et al., 1988). In the context of the COVID-19 pandemic, substantial personal and social resource losses (e.g., financial and interpersonal losses) may be caused by the lockdowns and social distancing. People may feel like losing control over their future as the COVID-19 pandemic is unpredictable. Social distancing and home-staying policies may have resulted in boredom (loss in fun) and potential losses in social relationships. The stress may also overspill to adversely affect family relationships. The development of the tool is guided by such domains.

It is warranted to develop a tool to advance research on assessing the comprehensive types of resource losses due to COVID-19 at the community level, as such resource losses are multi-dimensional and impactful. A validated tool and its related research have far-reaching research and policy applications besides understanding mental distress and personal sufferings due to COVID-19. In brief, first, the tool can be used to monitor the changes in the levels and types of resource losses during and after the pandemic. Second, the tool can be used to assess the impacts of such resource losses (e.g., interpersonal resources) on the community's specific behavioral responses to COVID-19 (e.g., preventive measures such as social distancing and lifestyle changes such as alcohol use). Third, it can be used to collect information that facilitates resource allocations for compensating serious resource losses in 
specific populations. Fourth, it can be used in surveillance that informs adjustment of levels of control measures that balance between prevention of COVID-19 and severity of losses. The tool thus has potentials to contribute to research and improvements regarding personal and interpersonal well-being, as well as policy formulations.

Despite the potential significance, no COR tool has been developed for any pandemic. The existing COR scales are inappropriate for COVID-19 research as they have not been contextualized to COVID-19. For instance, one of the COR tools is the 74-item COR-Evaluation (COR-E) (Hobfoll, 1988), which has been applied to research on stress responses to pregnancy (Wells et al., 1999) and chronic fatigue syndrome (Taylor et al., 2006), but not to emerging infectious diseases. Some studies created their own COR scales to capture features of the specific negative events. For instance, one study adapted a 9-item COR-E to assess resource losses during the 'Umbrella movement' in Hong Kong; it found that personal and social resource losses were associated with anxiety and depressive symptoms (Hou et al., 2015). Two revised 42-item and 19-item COR-E measured resource losses due to natural disasters (e.g., hurricane (Benight et al., 1999) and earthquake (Freedy et al., 1994)). The development and validation of the COR scale in this study are thus novel. It extends the application of the COR theory to COVID-19 which is a new and one of the most important global health problems.

Given the background, this study developed the 5-domain Conservation of Resources Scale for COVID-19 (CORSCOVID-19), and validated it in a Chinese adult general population in Hong Kong, China. In the present study, the scale was developed by an expert team after conducting a thorough literature review. Confirmatory factors analysis (CFA) was conducted, while the results of exploratory factor analysis (EFA) were kept in an appendix. Other psychometric properties (floor and ceiling effects, internal consistency, content validity, convergent and concurrent validity) were then conducted for this scale and its subscales under the confirmed structure.

\section{Methods}

\section{Study Design and Contextual Background}

A random telephone survey was conducted among Chinese adults (aged $\geq 18$ years) during April 3-10, 2020 in Hong Kong. Different prevention measures such as class suspension, closure of government services, and boundary restriction of exit/entry had been exercised since January 26, 2020 in Hong Kong. Travel to mainland China was also restricted. Facemask wearing was almost universal although there was no legal requirement for the use during the study period. There was no lockdown although several types of entertainment venues (e.g., cinemas and fitness centers) were closed and schools and government services have been suspended from time to time. Social distancing measures were exercised that gathering size in public areas was restricted to $\leq 4$ persons from March 29 to May 4, 2020 when the study was conducted. The economy was severely affected as the tourist, retail, catering, and transportation industries were badly hit; the unemployment rate started increasing from $3.4 \%$ in January to 5.2\% in April 2020 (and 7.2\% as of February 2021). Thus, people in Hong Kong, like those living elsewhere, experienced potential losses in financial, interpersonal (family/social), and entertainment resources. As of April 10, 2020, the global/local cumulative number of COVID-19 cases and deaths were $1,521,252 / 989$ and $92,798 / 4$, respectively.

\section{Data Collection}

All telephone interviews were conducted between 6 and 10:30 pm (10-15 $\mathrm{min})$ by experienced interviewers to avoid over-sampling non-working individuals. Telephone numbers were randomly drawn from the most updated residential telephone directory. Unanswered telephone calls were given at least three attempts before being classified as invalid. A total of 300 participants completed the interview. No incentives were given to the participants. Verbal informed consent was obtained from the participants and the ethics approval was obtained from the research ethics committee of the corresponding author's institution. The response rate, defined as the number of completed interviews divided by the number of eligible respondents, was $56.2 \%$.

\section{Measures}

Background Variables Information about the participants' sex, age, current marital status, and educational level was collected.

The CORS-COVID-19 The 16-item scale was constructed to assess the extent of five domains of resource losses due to the COVID-19 pandemic (loss in financial resource, loss in family resource, loss in future control, loss in fun, and loss in social resource). A multidisciplinary panel consisting of experienced epidemiologist, psychologist, and behavioral scientist was set up for the scale development concerning item generation, item development, and item selection. According to the developer of the COR theory, the theory has the three constructs of material, personal, and interpersonal losses (Hobfoll, 2001, 2004b, 2012). Such constructs were used to guide item generation. The panel derived seven domains under the three constructs, according to a literature review of the negative impacts of COVID-19 (Choi et al., 2020; El-Zoghby et al., 2020; Venkatesh \& Edirappuli, 2020; Wilson et al., 2020); two of them were removed from the list (loss in resource of 
career prospective and in health-seeking resource). The panel then generated an item pool, from which 3-4 items were selected for each of the five retained domains of the COR theory. Two researchers cross-checked the content validity of the final items by consensus. The items were rated by using three-point Likert scales (no loss at all/loss to some extent/loss to a great extent); higher scores indicated higher levels of resource loss due to COVID-19.

\section{External Variables}

Four external variables were used to testing convergent validity: 1) Potential Financial Problems due to COVID-19. The two single items were: a) "If the COVID-19 pandemic would last over a year, your family would face serious financial problems" ( $1=$ extremely disagree to $5=$ extremely agree $)$, and b) "Have you felt unrest due to incidence of lay-off/reduced salary/no-pay leave since the outbreak of the COVID19 pandemic?" ( $1=$ nil to $5=$ extremely). 2) Social Support Scale (Family). It included two items that assessed the levels of perceived emotional and instrumental support from family members $(1=$ extremely disagree to $7=$ extremely agree $)$. The Cronbach's alpha was 0.86 in this study. The scale has been used in previous publications (Li et al., 2017). 3) Hopelessness. A single item was selected from the 4-item Beck's Hopelessness Scale (Aish \& Wasserman, 2001): "My future seems dark to me" $(1=$ extremely disagree to $6=$ extremely agree). Previous studies have used this single item to represent the Beck's Hopelessness Scale (Oyekcin et al., 2017; Sisask et al., 2008). A validation study showed that the item's performance in predicting suicidal attempts was comparable to that of the original 4-item scale (ROC area was $67 \%$ versus $72 \%$ ) (Yip \& Cheung, 2006). Furthermore, another study found that this single item showed a very strong factor loading (0.98) and argued that "one single item, "the future looks dark to me' would be sufficient, because it measures hopelessness almost perfectly (0.98) (p.371)" (Aish \& Wasserman, 2001). Hence, the item was used in this study.

Two external variables were used to test concurrent validity: 1) Emotional Distress due to COVID-19 Scale. Three items were used to assess levels of emotional distress [i.e., panic, anxiety, and emotional agitation due to the COVID19 pandemic $(1=$ very low to $5=$ very high $)]$. The Cronbach's alpha was 0.93 in this study. The scale has been used in a number of publications (Yeung et al., 2017). 2) Satisfaction with living in Hong Kong. The single item was "Overall, living in Hong Kong makes you feel satisfied." $(1=$ extremely disagree to $7=$ extremely agree $)$.

\section{Statistical Analysis}

Internal consistency was assessed by Cronbach's alpha coefficients. Item-scale and item-subscale Pearson correlation coefficients ( $r$ ) were derived. The overall scale and the subscales would be considered as having floor/ceiling effects if more than $15 \%$ of the participants possessed the minimum/ maximum scores of the respective overall scale/subscales.

CFA with maximum likelihood estimation was conducted; Goodness-of-fit statistics and cut-off criteria for CFA were: Chi-square/df ratio $<5.00$, Non-Normed Fit Index $(\mathrm{NNFI})$ $>0.90$, Comparative Fit Index (CFI) $>0.90$, and Root Mean Square Error of Approximation (RMSEA) $<0.08$ (Wang \& Wang, 2019). Since the deductive scale development approach was used to develop a new scale based on the COR theory, our purpose is to confirm the theoretical structure of the five domains derived from the COR constructs, instead of those generated from the data through EFA. CFA is thus used for the purpose, as "CFA is applied to test the extent to which a researcher's a-priori, theoretical pattern of factor loadings pre-specified constructs represents the actual data (p.669)" (Hair et al., 2009).

As a supplementary analysis, EFA was conducted. The common factor analysis (maximum likelihood) and oblique rotation (Promax) to extract factors from the 16-item CORSCOVID-19 was performed. The number of items to be extracted was determined by a combination of scree plot, the conventional Kaiser criteria (i.e., eigenvalue $>1.0$ ), and Horn's parallel analysis (i.e., derivation of the expected eigenvalues by simulating normal random samples that parallel the observed data in terms of sample size and the number of variables based on Monte Carlo simulation process) (Pontes \& Griffiths, 2015).

Convergent/concurrent validity was established by inspecting Pearson correlation coefficients ( $r$ ) between the scale/subscale scores and the selected external variables. First, four of external variables were selected to test convergent validity; they were hence similar to some of the subscales: a) the correlations between the two single items of potential financial problems and the domain of loss in financial resource; $b$ ) the correlation between the hopelessness item and loss in future control, and c) the correlation between the family support scale and loss in family resource. Second, two external variables (emotional distress due to COVID-19 scale and satisfaction with living in Hong Kong) were used to test the concurrent validity (i.e., significant correlations between the subscales and some potential outcomes). The selection of these two external variables was supported by both the COR theory and empirical studies, which have shown that resource losses were significant predictors of psychological distress (e.g., mental distress) and psychological well-being (e.g., life satisfaction) under stressful circumstances (e.g., disasters and political movements) (Benight et al., 1999; Hobfoll, 2004a, 2004b; Hou et al., 2015).

CFA was conducted by using AMOS 17.0 while the other tests were analyzed by SPSS 21.0. Statistical significance was defined as $p<.05$ (two-tailed tests). 


\section{Results}

\section{Characteristics of the Participants}

Of the 300 participants, over half were females $(62.0 \%)$, aged $>55$ years $(53.7 \%)$, and being currently married or cohabitating with someone (63.3\%). $20 \%$ and $33.3 \%$ had received at least $\leq 6$ years and $\geq 12$ years of formal education, respectively (see Table S1).

The frequencies of the items representing particular types of losses are presented in Table 1 . Of the 16 items, the percentages of participants who endorsed 'loss to some extent' and 'loss to a great extent' ranged from $13.3 \%$ to $49.7 \%$ and $3.7 \%$ to $40.7 \%$, respectively. The average item scores within each of the five subscales (in descending order; range $=1$ to 3 ) were: 2.18 (loss in fun), 1.83 (loss in financial resource), 1.78 (loss in social resource), 1.75 (loss in future control), and 1.23 (loss in family resource). The average percentage of participants who reported resource loss to a great extent of the items within each of the five subscales (in descending order) were: 36.4\% (loss in fun), 20.7\% (loss in financial resource), 19.9\% (loss in social resource), $17.4 \%$ (loss in future control), and $4.0 \%$ (loss in family resource).

\section{Confirmatory Factor Analysis}

The results are presented in Table 2, the CFA demonstrated satisfactory model fit of the proposed 5-factor structure deduced from the theoretical COR constructs (Chi-square/ $d f=$ $2.78, \mathrm{CFI}=0.95, \mathrm{NNFI}=0.92$, and RMSEA $=0.08$ ); the standardized path estimates ranged from 0.56 to 0.97 (all $p<.001)$. The five subscales were all positively correlated with the overall COR scale ( $r$ ranged from 0.56 to 0.80 ; $p<.001)$; the subscales were positively correlated with each other $(r$ ranged from 0.27 to $0.58 ; p<.001)$.

\section{Exploratory Factor Analysis}

As a supplementary analysis, the results are shown in Table S2. The Kaiser-Meyer-Olkin Measure of Sampling Adequacy $(\mathrm{KMO}=0.84)$ and Bartlett's Test of Sphericity [Chi-square $(d f=120)=3331.11, p<.001]$ were satisfactory. The item retention criteria were factor loadings larger or equal to $0.40 \mathrm{and} /$ or the difference of parallel loading $<0.20$. The five factors generated by the EFA according to a set of combined criteria (i.e., scree plot, eigenvalue $>1$, and Horn's parallel analysis) matched exactly with the five deductive domains of the COR theoretic structure (i.e., loss in financial
Table 1 Frequencies and proportions of the response options of items in the Conservation of Resource Scale for COVID-19

\begin{tabular}{|c|c|c|c|}
\hline \multirow[t]{2}{*}{ Items } & \multicolumn{3}{|c|}{ Response options } \\
\hline & $\begin{array}{l}\text { No loss at all } \\
\mathrm{n}(\%)\end{array}$ & $\begin{array}{l}\text { Loss to some extent } \\
\text { n }(\%)\end{array}$ & $\begin{array}{l}\text { Loss to a great extent } \\
\mathrm{n}(\%)\end{array}$ \\
\hline \multicolumn{4}{|l|}{ Loss in financial resource } \\
\hline Income & $116(38.7)$ & $108(36.0)$ & $76(25.3)$ \\
\hline Savings & $104(34.7)$ & $127(42.3)$ & $67(22.3)$ \\
\hline Assets & $100(33.3)$ & $127(42.3)$ & $73(24.3)$ \\
\hline Financial difficulty & $155(51.7)$ & $95(31.7)$ & $50(16.7)$ \\
\hline \multicolumn{4}{|l|}{ Loss in family resource } \\
\hline Family relationship & $249(83.0)$ & $40(13.3)$ & $11(3.7)$ \\
\hline More conflicts & $245(81.7)$ & $44(14.7)$ & $11(3.7)$ \\
\hline Less communication & $238(79.3)$ & $48(16.0)$ & $14(4.7)$ \\
\hline \multicolumn{4}{|l|}{ Loss in future control } \\
\hline More difficult to control one's future & $126(42.0)$ & $120(40.0)$ & $54(18.0)$ \\
\hline Lose hope toward future & $141(47.0)$ & $114(38.0)$ & $45(15.0)$ \\
\hline Instability of life & $115(38.3)$ & $127(42.3)$ & $58(19.3)$ \\
\hline \multicolumn{4}{|l|}{ Loss in fun } \\
\hline Fun in life & $51(17.0)$ & 149 (49.7) & $100(33.3)$ \\
\hline Entertainment (out of home) & $37(12.3)$ & $141(47.0)$ & $122(40.7)$ \\
\hline Travels & $79(26.3)$ & $115(38.3)$ & $106(35.3)$ \\
\hline \multicolumn{4}{|l|}{ Loss in social resources } \\
\hline Social support from friends & $152(50.7)$ & $111(37.0)$ & $37(12.3)$ \\
\hline Meetings with friends & $68(22.7)$ & $130(43.3)$ & $102(34.0)$ \\
\hline Closeness with friends & 155 (51.7) & $105(35.0)$ & $40(13.3)$ \\
\hline
\end{tabular}


Table 2 Confirmatory factor analysis and item analysis of the Conservation of Resource Scale for COVID-19 $(n=300)$

\begin{tabular}{|c|c|c|c|c|}
\hline Items & $\begin{array}{l}\text { Path estimate } \\
\left(\mathrm{CFA}^{\mathrm{II}}\right)\end{array}$ & $\begin{array}{l}\text { Item-scale scale } \\
\text { correlation }\end{array}$ & $\begin{array}{l}\text { Item-subscale } \\
\text { correlation }\end{array}$ & $\begin{array}{l}\text { Item-other subscale correlation } \\
\text { (range) }\end{array}$ \\
\hline \multicolumn{5}{|l|}{ Factor 1: Loss in financial resource } \\
\hline Item 1: Income & $0.86^{* * *}$ & $.71 * * *$ & $.90 * * *$ & $.20 * * * \sim .52 * * *$ \\
\hline Item 2: Savings & $0.92 * * *$ & $.71 * * *$ & $.92 * * *$ & $.22 * * * \sim .49 * * *$ \\
\hline Item 3: Assets & $0.84 * * *$ & $.69 * * *$ & $.87 * * *$ & $.23 * * * \sim .51 * * *$ \\
\hline Item 4: Financial difficulty & $0.75 * * *$ & $.70 * * *$ & $.84 * * *$ & $.30 * * * \sim .53 * * *$ \\
\hline \multicolumn{5}{|l|}{ Factor 2: Loss in family resource } \\
\hline Item 5: Family relationship & $0.97 * * *$ & $.54 * * *$ & $.93 * * *$ & $.24 * * * \sim .36 * * *$ \\
\hline Item 6: More conflicts & $0.87 * * *$ & $.53 * * *$ & $.89 * * *$ & $.22 * * * \sim .37 * * *$ \\
\hline Item 7: Less communication & $0.65 * * *$ & $.49 * * *$ & $.83 * * *$ & $.25 * * * \sim .40 * * *$ \\
\hline \multicolumn{5}{|l|}{ Factor 3: Loss in future control } \\
\hline $\begin{array}{l}\text { Item 8: More difficult to control one's } \\
\text { future }\end{array}$ & $0.91 * * *$ & $.73 * * *$ & $.94 * * *$ & $.34 * * * \sim .48 * * *$ \\
\hline Item 9: Lose hope toward future & $0.96^{* * *}$ & $.76^{* * *}$ & $.95 * * *$ & $.35 * * * \sim .54 * * *$ \\
\hline Item 10: Instability of life & $0.80 * * *$ & $.73 * * *$ & $.90 * * *$ & $.33 * * * \sim .60 * * *$ \\
\hline \multicolumn{5}{|l|}{ Factor 4: Loss in fun } \\
\hline Item 11: Fun in life & $0.92 * * *$ & $.63 * * *$ & $.90 * * *$ & $.25^{* * *} \sim .40^{* * *}$ \\
\hline Item 12: Entertainment (out of home) & $0.93 * * *$ & $.60 * * *$ & $.92 * * *$ & $.24 * * * \sim .39 * * *$ \\
\hline Item 13: Travels & $0.60 * * *$ & $.58 * * *$ & $.82 * * *$ & $.28 * * * \sim .39 * * *$ \\
\hline \multicolumn{5}{|l|}{ Factor 5: Loss in social resource } \\
\hline Item 14: Social support from friends & $0.86^{* * *}$ & $.63 * * *$ & $.87 * * *$ & $.34 * * * \sim .40 * * *$ \\
\hline Item 15: Meetings with friends & $0.56^{* * *}$ & $.50 * * *$ & $.78 * * *$ & $.24 * * * \sim .29 * * *$ \\
\hline Item 16: Closeness with friends & $0.79 * * *$ & $.59 * * *$ & $.84 * * *$ & $.29 * * * \sim .45^{* * *}$ \\
\hline
\end{tabular}

${ }^{\mathbb{I}}$ The model fit index for the CFA were Chi-square $/ d f=261.07 / 94=2.78(p<.001), \mathrm{CFI}=0.95, \mathrm{NNFI}=0.93, \mathrm{NFI}=0.92$, and RMSEA $=0.08 ; * * *$, $p<.001$

resource, loss in family resource, loss in future control, loss in fun, and loss in social resource). The eigenvalues of the five extracted factors were $6.53,1.61,2.08,1.31$, and 1.03 , which explained $40.8 \%, 10.1 \%, 13.0 \%, 8.2 \%$, and $6.4 \%$ of the total variance, respectively (the five factors together explained $78.5 \%$ of the total variance).

\section{Item and Subscale Analyses}

The mean (SD; range) scores of the overall scale and the five subscales of the CORS-COVID-19 were 28.1 (overall scale: $7.1 ; 16-48$ ), 7.3 (loss in financial resource: $2.7 ; 4-12$ ), 3.7 (loss in family resource: $1.3 ; 3-9$ ), 5.3 (loss in future control: 2.0; 3-9), 6.5 (loss in fun: 1.9; 3-9), and 5.3 (loss in social resource: $1.8 ; 3-9$ ), respectively. Four subscales (loss in family resources: $23.7 \%$; loss in future control: $71.3 \%$; loss in fun: $31.0 \%$; loss in social resource: $20.3 \%$ ) detected some floor effects. No ceiling effect was detected for the overall scale and all but one of the subscales (loss in fun: 23.0\%). (see Table 3).

The Cronbach's alpha values of the overall scale and its five subscales ranged from 0.77 to 0.92 (see Table 3). The item-scale correlation coefficients ranged from 0.49 to 0.76 ; the item-subscale correlation coefficients ranged from 0.78 to 0.94 ( $p<.001$ for all the correlations). All correlation coefficients between the individual items and their respective subscales were higher than those between the items and the other four subscales (see Table 2). Besides, the scores of the overall scale and five subscales were all positively correlated with each other (Pearson correlation coefficients ranged from 0.27 to 0.80 , all $p<.001)$.

\section{Concurrent and Convergent Validity}

Regarding concurrent validity, the results presented in Table 4 show that the overall scale and the five subscales of the CORS-COVID-19 were positively and significantly correlated with emotional distress due to COVID-19 ( $r$ ranged from 0.23 to $0.42 ; p<.001)$ and negatively and significantly correlated with satisfaction with living in Hong Kong ( $r$ ranged from -0.41 to $-0.18 ; p<.01$ ). Regarding convergent validity, 1) the subscale of loss in financial resource was significantly and positively correlated with the two single items of potential financial problems due to COVID-19 ( $r=0.42$ and 0.52, respectively; $p<.001), 2$ ) the subscale of loss in future control was positively and significantly correlated with hopelessness 
Table 3 Scale and subscale analysis of the Conservation of Resource Scale for COVID-19 ( $\mathrm{n}=300)$

\begin{tabular}{llllll}
\hline & Range & Mean, SD & $\begin{array}{l}\text { Floor effect } \\
(\%)\end{array}$ & $\begin{array}{l}\text { Ceiling effect } \\
(\%)\end{array}$ & $\begin{array}{l}\text { Internal consistency } \\
\text { (Cronbach's alpha) }\end{array}$ \\
\hline Overall scale & $16-48$ & $28.1,7.1$ & 3.0 & 1.7 & 0.90 \\
Factor 1: Loss in financial resource & $4-12$ & $7.3,2.7$ & 23.7 & 12.7 & 0.91 \\
Factor 2: Loss in family resource & $3-9$ & $3.7,1.3$ & 71.3 & 2.3 & 0.86 \\
Factor 3: Loss in future control & $3-9$ & $5.3,2.0$ & 31.0 & 13.0 & 0.92 \\
Factor 4: Loss in fun & $3-9$ & $6.5,1.9$ & 9.7 & 23.0 & 0.84 \\
Factor 5: Loss in social resource & $3-9$ & $5.3,1.8$ & 20.3 & 8.7 & 0.77 \\
\hline
\end{tabular}

$(r=0.14 ; p=.015)$, and 3$)$ the subscale of loss in family resource was negatively and significantly correlated with support from family members $(r=-0.16 ; p=.005)$.

\section{Discussion}

The COVID-19 pandemic has changed many aspects of people's daily life worldwide, including jobs, lifestyle, social interactions, and travels. Such changes are often stressful and may reflect causes and results of resource losses due to the pandemic. Although some people may have resource gain due to COIVD-19, resource loss is more important than resource gain, according to the COR theory (Hobfoll, 1988, 1989, 2004a, 2011). Furthermore, it is uncertain whether resource losses due to COVID-19 would persist and worsen. The uncertainty increases loss in future control in the general population.

The COVID-19 pandemic in Hong Kong was under control during and after the study period which was April 3-10, 2020 (989 reported COVID-19 cases in Hong Kong as of April 10, 2020). People have not been restricted to stay home and the unemployment rate was still relatively mild during the study period (5.2\% as of April 2020). However, the data shows that the levels of the five types of resource losses were substantial. For instance, over $1 / 3$ of the participants reported to a great extent of loss in fun, and about $1 / 5$ reported to a great extent loss in financial resources, future control, and social relationships. It is interesting that, among the five types of losses, loss in fun was the most commonly reported, possibly due to social distancing and inability to travel. Attention should be given to boredom which was significantly associated with mental health problems (Sommers \& Vodanovich, 2000); alternative online social and entertainment activities are warranted. Loss in family relationship was the mildest among the five types of losses, plausibly because Chinese families tend to be cohesive in face of adversities and disasters (Shi et al., 2013).

It is contended that the losses may have become even more serious overtime in Hong Kong and other places. There are substantial variations in resource losses across countries, as there are differences in the number of confirmed cases, governmental measures, behavioral responses, and socio-cultural contexts. It is also contended that some countries may even report more severe losses in financial resources than Hong Kong, as they have a far large number of COVID-19 cases and prolonged lockdowns. Thus, comparisons across countries and time are important and allow for better evaluation of the global negative consequences of the COVID-19 pandemic. The new tool allows for studying such research questions.

This study developed and validated a new COR tool regarding COVID-19 (CORS-COVID-19). It can be used to assess five types of resource losses in three domains: material loss (loss in financial resource), personal loss (loss in future control and loss in fun), and social loss (loss in family resource and loss in social resource). The 5-factor structure was derived deductively from the three constructs of the COR theory, and was strongly supported by the results of the CFA. Further
Table 4 Correlations between the Conservation of Resource Scale for COVID-19 and two external variables $(n=300)$

\begin{tabular}{lll}
\hline & $\begin{array}{l}\text { Emotional distress due } \\
\text { to COVID-19 }\end{array}$ & $\begin{array}{l}\text { Satisfaction with living } \\
\text { in Hong Kong }\end{array}$ \\
\hline Overall scale & $0.42 * * *$ & $-0.41^{* * *}$ \\
Factor 1: Loss in financial resource & $0.34 * * *$ & $-0.27 * * *$ \\
Factor 2: Loss in family resource & $0.25^{* * *}$ & $-0.18^{* *}$ \\
Factor 3: Loss in future control & $0.34 * * *$ & $-0.40^{* * *}$ \\
Factor 4: Loss in fun & $0.23 * * *$ & $-0.35^{* * *}$ \\
Factor 5: Loss in social resource & $0.33^{* * *}$ & $-0.27 * * *$ \\
\hline
\end{tabular}

$* *, p<.01 ; * * *, p<.001$ 
supplementary support was given by the EFA, which also identified a clear 5-factor structure that was the same as the aforementioned ones developed deductively from the COR theory.

In general, satisfactory psychometric properties were observed, such as sound internal consistency, content validity (the correlation coefficients being stronger between items and their respective subscales, and weaker between items and the other four subscales). To some extent, convergent validity was illustrated by the positive correlations between loss in financial resource and external variables of financial issues, between loss in family resource and perceived family support, and between loss in future control and hopelessness. The performance of the tool is hence acceptable.

It is noteworthy to point out that four subscales presented some floor effects (loss in financial resource, family resource, future control, and social resource); one subscale presented ceiling effect (loss in fun). It is expected that the floor effect of this scale would be smaller if it were used in more severely hit places and times. It is possible that the narrow range of the 3-point Likert scales (no loss at all/loss to some extent/loss to a great extent) might have led to higher likelihoods of having floor/ceiling effects; 5-point or 7-point Likert scales may be utilized in the future refinement of the scale. It is thus a potential limitation that the 3-point scales were used, instead of the 5-point or 7-point Likert scales to solicit responses about resource losses. However, unlike other 5 or 7 -point scales, the developed tool only measured one direction of potential changes (i.e., losses) and three points seem adequate, as labeling of five/seven response categories in one direction of loss might be difficult to understand.

Furthermore, the significant positive associations between the overall scale/subscales and the two external variables of emotional distress due to COVID-19 and satisfaction with living in Hong Kong demonstrated acceptable concurrent validity. The findings supported the COR theory's postulation that resource loss determines stress responses and causes mental distress (Hobfoll, 1988, 1989, 2004a, 2011). Such correlations with the external variables were supported by some COVID-19 studies. For instance, job insecurity, which is similar to loss in financial resource and loss in future control, was associated with depression and anxiety during the COVID-19 pandemic (Wilson et al., 2020); increased loneliness and decreased social support due to social distancing, which are similar to the loss in social resource during the COVID-19 pandemic, were associated with mental health problems such as depression (Marroquín et al., 2020). Future studies are warranted to confirm the associations between the new COR scale and mental distress related to COVID-19.

The tool is a novel one as it is the first and only COR scale developed to assess comprehensive types of resource losses due to any pandemic or emerging infectious diseases. It has a wide range of potential research applications and contributions. 1) The tool can be used to analyze the uneven levels of resource losses due to COVID-19 and the specific impact of different types of resource loss. For instance, financial losses and interpersonal losses would have differential strength of impacts on mental distress. Such understanding would facilitate the government to allocate its resources properly and effectively to compensate specific types of resource losses that are sizable and/or seriously consequential. 2) The new tool can be used in serial surveillance and/or cohort studies to trace the community's changes in specific resource losses over time and their changing impacts on mental distress and behavioral responses during different phases of the pandemic. This function is potentially important as the governments need to balance between intensity of the public health measures and people's 'tolerance' of resource losses resulted from such measures continuously. Surveillance of changes in resource losses over time would allow the governments to loosen/tighten lockdowns, social distancing, and other preventive policies over time and when appropriate. With baselines established, the tool can also be used to trace recoveries from the pandemic as indicated by reduction in resource losses when vaccination has attained a high population coverage and life starts resuming to normal. 3) The tool can be used to identify subpopulations that have more serious losses and/or facing stronger impacts of the losses. Researchers are able to identify groups that need extra help and/or reveal inequity regarding some social groups. 4) The tool can be translated and validated in other languages, thus allowing for cross-cultural comparative research. Such studies allow us to understand better issues such as different patterns of resource losses in different countries, and possibly some clues on why people in some countries were not supportive of control policies. It can thus help to attain an important and systematic understanding of the global negative impacts of the COVID-19 pandemic. 5) The tool extends applications of the COR theory to understand community emotional/behavioral responses to COVID-19 and possibly other future pandemics. It can also be used to investigate factors of preventive behaviors and lifestyle changes (e.g., binge drinking). It is argued that COVID-19 research would be incomplete without looking at resource losses. The scale will thus contribute to future COVID-19 research.

This study has several limitations. Those about the relatively small sample size and the use of a 3-point Likert scale have been mentioned. Furthermore, the sample included more people of a higher age than the census data, as $29.7 \%$ of the sample aged $>65$ (versus $21.4 \%$ in census data). Other types of resource losses may be important but have not been included in the scale. For instance, loss in career perspective was not included in the scale as some older participants and housewives were out of the job market. It is recommended to expand this scale by adding other important components. Social desirability bias may exist when it came to sensitive questions such as household financial problems. Moreover, the scale development process did not involve an inductive approach, i.e., the items were not generated by 
interviewing a group of respondents, as there were strict social distancing control measures and people need to work from home during the study period; meetings were not feasible. Furthermore, it is ideal to conduct EFA and CFA in separate samples, as CFA may over-fit models derived by EFA from the same sample (Hinkin, 1998). It is another limitation that our sample size was too small for creating split samples for conducting both EFA and CFA. Instead, both CFA and the supplementary EFA were based on the same sample. Similar cases of not involving split (or independent) samples but using a single sample in deductive scale development are common in literature (Morgado et al., 2017). Besides, some factor loadings in the EFA were negative; the sizes were very small (mostly <0.05) and were hence acceptable as the finding implies that an item did not load on a particular factor that gives it a very small loading.

In conclusion, this study has newly developed and validated the CORS-COVID-19 that consists of five factors (i.e., loss in financial resource, loss in family resource, loss in future control, loss in fun, and loss in social resource), which showed satisfactory psychometric properties. The validated tool has implications for future studies. First, the tool can be refined to assess resource losses in multiple populations (especially disadvantaged groups), different countries, and different phases of the COVID-19 pandemic. Second, using the validated tool may contribute to advancing various types of COVID-19 related research on mental distress (e.g., testing the application of the COR theory in the context of COVID19). Third, the tool may be modified to assess resource loss due to other emerging infectious diseases and future pandemics. Besides, it is important to expand the tool to cover resource gain due to COVID-19, although most of the COR studies only focused on resource loss. All in all, the tool can potentially contribute to advance various types of COVID-19related research on mental distress.

Supplementary Information The online version contains supplementary material available at https://doi.org/10.1007/s12144-021-01933-y.

Funding Source The study was supported by the internal research funding of the Centre for Health Behaviours Research. The funding source had no involvement in this study.

Author's Contribution Conceptualization: JTFL and YY; Methodology: YY and JTFL; Investigation: MMCL; Software: YY; Formal analysis: YY; Data curation: YY; Validation: JTFL; Resources: JTFL; Writingoriginal draft: YY and JTFL; Writing-review \& editing: YY and JTFL; Supervision: JTFL; Funding acquisition: JTFL.

Data Availability Data not available due to ethical restrictions.

\section{Declarations}

Ethic Statement The study was approved by the Survey and Behavioral Research Ethics Committee of the Chinese University of Hong Kong (No. SBRE-19-660).
Conflict of Interest The authors declared no conflicts of interest.

\section{References}

Adalja, A. A., Toner, E., \& Inglesby, T. V. (2020). Priorities for the US health community responding to COVID-19. JAMA, 323(14), 1343-1344. https://doi.org/10.1001/jama.2020.3413.

Aish, A.-M., \& Wasserman, D. (2001). Does Beck's hopelessness scale really measure several components? Psychological Medicine, 31(2), 367-372. https://doi.org/10.1017/S0033291701003300.

Bartik, A. W., Bertrand, M., Cullen, Z. B., Glaeser, E. L., Luca, M., \& Stanton, C. T. (2020). How are small businesses adjusting to COVID-19? Early evidence from a survey. National Bureau of Economic Research, 26989. https://doi.org/10.3386/w26989.

Benight, C. C., Ironson, G., Klebe, K., Carver, C. S., Wynings, C., Burnett, K., Greenwood, D., Baum, A., \& Schneiderman, N. (1999). Conservation of resources and coping self-efficacy predicting distress following a natural disaster: A causal model analysis where the environment meets the mind. Anxiety, Stress and Coping, 12(2), 107-126. https://doi.org/10.1080/ 10615809908248325 .

Blaze, J. T., \& Shwalb, D. W. (2009). Resource loss and relocation: A follow-up study of adolescents two years after hurricane Katrina. Psychological Trauma: Theory, Research, Practice, and Policy, 1(4), 312-322. https://doi.org/10.1037/a0017834.

Bouali, H., Okereke, M., Adebisi, Y. A., \& Lucero-Prisno III, D. E. (2020). Impact of COVID-19 on pharmacy education. SciMedicine Journal, 2, 92-95. https://doi.org/10.28991/SciMedJ-2020-02-SI-8.

Choi, E. P. H., Hui, B. P. H., \& Wan, E. Y. F. (2020). Depression and anxiety in Hong Kong during COVID-19. International Journal of Environmental Research and Public Health, 17(10), 3740. https:// doi.org/10.3390/ijerph17103740.

Diener, E., Oishi, S., \& Lucas, R. E. (2003). Personality, culture, and subjective well-being: Emotional and cognitive evaluations of life. Annual Review of Psychology, 54(1), 403-425. https://doi.org/10. 1146/ANNUREV.PSYCH.54.101601.145056.

El-Zoghby, S. M., Soltan, E. M., \& Salama, H. M. (2020). Impact of the COVID-19 pandemic on mental health and social support among adult Egyptians. Journal of Community Health, 45, 689-695. https://doi.org/10.1007/s10900-020-00853-5.

Freedy, J. R., Saladin, M. E., Kilpatrick, D. G., Resnick, H. S., \& Saunders, B. E. (1994). Understanding acute psychological distress following natural disaster. Journal of Traumatic Stress, 7(2), 257273. https://doi.org/10.1007/BF02102947.

Hair, J. F., Black, W. C., Babin, B. J., Anderson, R. E., Tatham, R. L. (2009) Multivariate data analysis, 7th Edition: Pearson.

Hall, B. J., Murray, S. M., Galea, S., Canetti, D., \& Hobfoll, S. E. (2015). Loss of social resources predicts incident posttraumatic stress disorder during ongoing political violence within the Palestinian authority. Social Psychiatry and Psychiatric Epidemiology, 50(4), 561568. https://doi.org/10.1007/s00127-014-0984-z.

Hinkin, T. R. (1998). A brief tutorial on the development of measures for use in survey questionnaires. Organization research methods, 1 , 104-121.

Hobfoll, S. E. (1988). The ecology of stress: Taylor \& Francis.

Hobfoll, S. E. (1989). Conservation of resources: A new attempt at conceptualizing stress. American Psychologist, 44(3), 513-524. https:// doi.org/10.1037/0003-066X.44.3.513.

Hobfoll, S. E. (2001). The influence of culture, community, and the nested-self in the stress process: Advancing conservation of resources theory. Applied Psychology, 50(3), 337-421. https://doi. org/10.1111/1464-0597.00062. 
Hobfoll, S. E. (2004a). Stress, culture, and community: The psychology and philosophy of stress. Springer Science \& Business Media. https://doi.org/10.1007/978-1-4899-0115-6.

Hobfoll, S. E. (2004b). Stress, culture, and community: The psychology and philosophy of stress: Springer Science \& Business Media.

Hobfoll, S. E. (2011). Conservation of resources theory: Its implication for stress, health, and resilience. The Oxford handbook of stress, health, and coping, 127-147. https://doi.org/10.1093/ OXFORDHB/9780195375343.013.0007.

Hobfoll, S. E. (2012). Conservation of resources and disaster in cultural context: The caravans and passageways for resources. Psychiatry: Interpersonal \& Biological Processes, 75(3), 227-232. https://doi. org/10.1521/psyc.2012.75.3.227.

Holmgrenn, L., Tirone, V., Gerhart, J., Hobfoll, S., Cooper, C., \& Quick, J. (2017). Conservation of resources theory: Resource caravans and passageways in health contexts. The handbook of stress and health: A guide to research and practice, 443-457. https://doi.org/10.1002/ 9781118993811.CH27.

Hou, W. K., Hall, B. J., Canetti, D., Lau, K. M., Ng, S. M., \& Hobfoll, S. E. (2015). Threat to democracy: Physical and mental health impact of democracy movement in Hong Kong. Journal of Affective Disorders, 186, 74-82. https://doi.org/10.1016/j.jad.2015.07.005.

House, J. S., Landis, K. R., \& Umberson, D. (1988). Social relationships and health. Science, 241(4865), 540-545. https://doi.org/10.1126/ SCIENCE.3399889.

Ilesanmi, O., \& Afolabi, A. (2020). Time to move from vertical to horizontal approach in our COVID-19 response in Nigeria. SciMedicine Journal, 2, 28-29. https://doi.org/10.28991/SciMedJ-2020-02-SI-3.

Li, J., Mo, P. K., Wu, A. M., \& Lau, J. T. (2017). Roles of self-stigma, social support, and positive and negative affects as determinants of depressive symptoms among HIV infected men who have sex with men in China. AIDS and Behavior, 21(1), 261-273. https://doi.org/ 10.1007/s10461-016-1321-1.

Liang, L., Gao, T., Ren, H., Cao, R., Qin, Z., Hu, Y., Li, C., \& Mei, S. (2020). Post-traumatic stress disorder and psychological distress in Chinese youths following the COVID-19 emergency. Journal of Health Psychology, 25(9), 1164-1175. https://doi.org/10.1177/ 1359105320937057.

Marroquín, B., Vine, V., \& Morgan, R. (2020). Mental health during the COVID-19 pandemic: Effects of stay-at-home policies, social distancing behavior, and social resources. Psychiatry Research, 293, 113419. https://doi.org/10.1016/j.psychres.2020.113419.

Morgado, F. F., Meireles, J. F., Neves, C. M., Amaral, A., \& Ferreira, M. E. (2017). Scale development: Ten main limitations and recommendations to improve future research practices. Psicologia: Reflexão $e$ Crítica, 30(3), 3. https://doi.org/10.1186/s41155-016-0057-1.

Oyekcin, D. G., Sahin, E. M., \& Aldemir, E. (2017). Mental health, suicidality and hopelessness among university students in Turkey. Asian Journal of Psychiatry, 29, 185-189. https://doi.org/10.1016/j. ajp.2017.06.007.

Pappa, S., Ntella, V., Giannakas, T., Giannakoulis, V. G., Papoutsi, E., \& Katsaounou, P. (2020). Prevalence of depression, anxiety, and insomnia among healthcare workers during the COVID-19 pandemic: A systematic review and meta-analysis. Brain, Behavior, and Immunity, 88, 901-907. https://doi.org/10.1016/j.bbi.2020.05.026.

Pontes, H. M., \& Griffiths, M. D. (2015). Measuring DSM-5 internet gaming disorder: Development and validation of a short psychometric scale. Computers in Human Behavior, 45, 137-143. https://doi. org/10.1016/j.chb.2014.12.006.

Qiu, J., Shen, B., Zhao, M., Wang, Z., Xie, B., \& Xu, Y. (2020). A nationwide survey of psychological distress among Chinese people in the COVID-19 epidemic: Implications and policy recommendations. General psychiatry, 33(2), e100213. https://doi.org/10.1136/ gpsych-2020-100213.

Rahmatipour, M. A., Ebadollahi-Natanzi, A., \& Arab-Rahmatipour, G. (2020). Letter to the editor: Prevention of depression and psychological stress by studying book in quarantine conditions of COVID19. SciMedicine Journal, 2(3), 182-183. https://doi.org/10.28991/ SciMedJ-2020-0203-7.

Ryan, D., Dooley, B., \& Benson, C. (2008). Theoretical perspectives on post-migration adaptation and psychological well-being among refugees: Towards a resource-based model. Journal of Refugee Studies, 21(1), 1-18. https://doi.org/10.1093/JRS/FEM047.

Shi, P., Liu, L., Xu, W., Fang, W., \& Wang, M. (2013). Experience, lessons and recommendation of China's response to the Wenchuan earthquake disaster Integrated Risk Governance (pp. 71-88): Springer.

Sisask, M., Värnik, A., Kolves, K., Konstabel, K., \& Wasserman, D. (2008). Subjective psychological well-being (WHO-5) in assessment of the severity of suicide attempt. Nordic Journal of Psychiatry, 62(6), 431-435. https://doi.org/10.1080/ 08039480801959273.

Sommers, J., \& Vodanovich, S. J. (2000). Boredom proneness: Its relationship to psychological-and physical-health symptoms. Journal of Clinical Psychology, 56(1), 149-155. https://doi.org/10.1002/(SICI) 1097-4679(200001)56:1<149::AID-JCLP14>3.0.CO;2-Y.

Taylor, R. R., Kulkarni, S., \& Shiraishi, Y. (2006). Conservation of resources and quality of life in individuals with chronic fatigue syndrome. Journal of Chronic Fatigue Syndrome, 13(4), 3-15. https:// doi.org/10.1300/J092V13N04_02.

Venkatesh, A., \& Edirappuli, S. (2020). Social distancing in covid-19: What are the mental health implications? BMJ, 369, m1379. https:// doi.org/10.1136/bmj.m1379.

Wang, J., \& Wang, X. (2019). Structural equation modeling: Applications using Mplus: John Wiley \& Sons.

Wells, J. D., Hobfoll, S. E., \& Lavin, J. (1999). When it rains, it pours: The greater impact of resource loss compared to gain on psychological distress. Personality and Social Psychology Bulletin, 25(9), 1172-1182. https://doi.org/10.1177/01461672992512010.

Wilson, J. M., Lee, J., Fitzgerald, H. N., Oosterhoff, B., Sevi, B., \& Shook, N. J. (2020). Job insecurity and financial concern during the COVID-19 pandemic are associated with worse mental health. Journal of Occupational and Environmental Medicine, 62(9), 686691. https://doi.org/10.1097/JOM.0000000000001962.

World Health Organization. (2021). Coronavirus disease (COVID-19) weekly epidemiological update and weekly operational update.

Yeung, N. C., Lau, J. T., Choi, K. C., \& Griffiths, S. (2017). Population responses during the pandemic phase of the influenza A (H1N1) pdm09 epidemic, Hong Kong, China. Emerging Infectious Diseases, 23(5), 813-815. https://doi.org/10.3201/eid2305.160768.

Yip, P. S., \& Cheung, Y. B. (2006). Quick assessment of hopelessness: A cross-sectional study. Health and Quality of Life Outcomes, 4(1), 16. https://doi.org/10.1186/1477-7525-4-13.

Yu, Y., She, R., Luo, S., Xin, M., Li, L., Wang, S., . . Zhao, J. (2021). Factors influencing depression and mental distress related to COVID-19 Among University students in China: Online crosssectional mediation study. JMIR Mental Health, 8(2), e22705. https://doi.org/10.2196/22705

Publisher's Note Springer Nature remains neutral with regard to jurisdictional claims in published maps and institutional affiliations. 